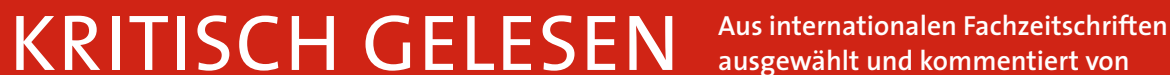

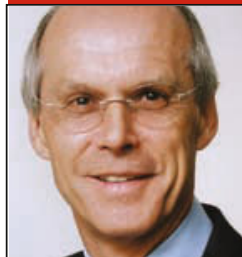

Prof. Dr. med. H. S. FüeßI Isar-AmperKlinikum, KI. MünchenOst, Haar

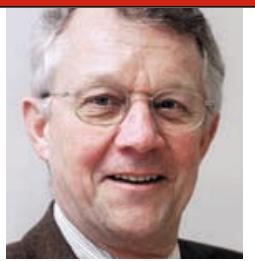

Prof. Dr. med. H. Holzgreve Internist, Kardiologische Praxis, München

\section{Testosteronsubstitution ist kein Jungbrunnen}

\section{Zwei gleichzeitig erschienene Publikationen belegen einmal mehr den Lehrsatz: Die Substitution eines Mangels macht nur Sinn, wenn po- sitive Wirkungen zuverlässig belegt sind.}

— Malkin et al. bestimmten bei $930 \mathrm{~Pa}$ tienten (mittleres Alter 61 Jahre) mit koronarer Herzkrankheit die Testosteron-

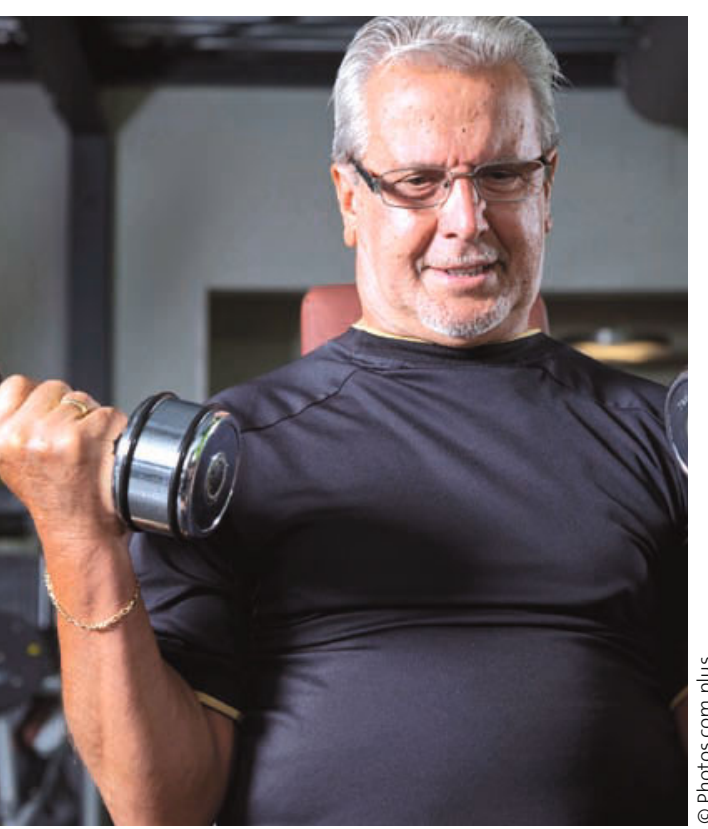

Das Alter geht auch an ihm nicht spurlos vorrüber. werte. Bei den Patienten mit niedrigen Werten (24\% der Gesamtkollektivs) lag nach einer Beobachtungsdauer von sieben Jahren die Sterblichkeit mit 21\% etwa doppelt so hoch wie bei jenen mit hohen Werten $(12 \%, p=0,002)$.

In der Studie von Basaria et al. erhielten 209 Patienten jenseits des 65. Lebensjahres mit niedrigen Testosteronwerten und Mobilitätseinschränkungen nach Zufallskriterien eine Behandlung mit Testosterongel oder Placebo. Nach sechs Monaten lagen die Testosteronwerte bei 574 bzw. $292 \mathrm{ng} / \mathrm{dl}$ in der
Verum- und Placebogruppe. Die Studie musste vorzeitig abgebrochen werden, weil bei den Patienten der Verumgruppe signifikant häufiger schwere, vorwiegend kardiovaskuläre Komplikationen auftraten.

\section{- C. J. Malkin et al.}

Low serum testosterone and increased mortality in men with coronary heart diaseas. Heart 96 (2010) 1821-1825

- S. Basaria et al.

Adverse events associated with testosterone administration. New Engl. J. Med. 363 (2010) 109-122

\section{Kommentar}

Mit den Jahren sinkt bei Männern der Testosteronspiegel. Das geht einher mit Altersbeschwerden wie Abnahme von Muskel- und Knochenmasse, körperlicher Kraft und Sexualfunktion. Wer nicht bereit ist, diesen körperlichen, psychischen und kognitiven Rückschritt als physiologische Alterung zu akzeptieren, versucht diese Entwicklung mit Anabolika zu verhindern oder zumindest hinauszuschieben. Androgene Steroide stehen zwar als Anti-Aging-Wundermittel hoch im Kurs, doch haben methodisch zuverlässige Studien bisher keinen nennenswerten Vorteil der Substitution nachweisen können (s. MMW 46/2006 und 12/2008). Das Ergebnis von Malkin et al., nämlich dass bei älteren Patienten mit niedrigen Testosteronspiegeln das kardivaskuläre Risiko erhöht ist, könnte ein weiterer Ansporn für eine Testosteronsubstitution sein. Doch gleichzeitig finden Basaria et al., dass diese Maßnahme die Zahl kardiovaskulärer Komplikationen steigert. Weil wir alle älter werden, wird die Suche nach dem Jungbrunnen und nach Lifestylemedikamenten zum Erhalt der ewigen Jugend weitergehen.

H. HolzG REVE 